\title{
Prevalence and Predictors of Oral Contraceptive Pills Use Among Yemeni Women in Dhamar Area
}

\author{
Amat Al-Khaleq O. Mehrass ${ }^{1,}$, , Abdulelah H. Al-Adhroey ${ }^{2}$, Abdullatif D. Ali ${ }^{3}$ \\ ${ }^{1}$ Department of Gynaecology and Obstetrics, Faculty of Medicine and Health Sciences, Thamar University, Dhamar, Yemen \\ ${ }^{2}$ Department of Medical Basic Sciences, Faculty of Medicine and Health Sciences, Thamar University, Dhamar, Yemen \\ ${ }^{3}$ Department of Biochemistry, Faculty of Medicine and Health Sciences, Thamar University, Dhamar, Yemen
}

Email address:

amatmehrass@gmail.com (A. Al-Khaleq O. Mehrass), husssien75@gmail.com (A. H. Al-Adhroey), abdullatifwhite@gmail.com (A. D. Ali)

\section{To cite this article:}

Amat Al-Khaleq O. Mehrass, Abdulelah H. Al-Adhroey, Abdullatif D. Ali. Prevalence and Predictors of Oral Contraceptive Pills Use Among Yemeni Women in Dhamar Area. American Journal of Health Research. Vol. 4, No. 1, 2016, pp. 1-5. doi: 10.11648/j.ajhr.20160401.11

\begin{abstract}
In the face of continuous efforts of the government and international organizations, population growth rate in Yemen still high. The present study was aimed to investigate the current prevalence and predictors of oral contraceptive pills (OCPs) use among Yemeni women in Dhamar area. A cross-sectional study was carried out among 400 women using a semi-structured questionnaire. The results showed that the prevalence rate of OCPs use is $33 \%$. General characteristics showed that almost half of the study population had no formal education, $>3$ living children, and $<20$ years at marriage. The predictors found to be significantly associated with OCPs use were age, educational level, age at marriage, number of living children, attitude on safety of OCPs, and practice on contraceptives-seeking behavior. The present study reported a rise in OCPs use and seeking behavior, but that was not consistent with the obstetric characteristics of the study population. Community mobilization with efficient health education would improve the awareness of Yemenis about the advantages of contraception in family well-being.
\end{abstract}

Keywords: Oral Contraceptive Pills, Prevalence, Predictors, Family Planning, Population Growth, Yemen

\section{Introduction}

Use of contraception including drugs, devices, or surgery for preventing pregnancy and planning family is highly required all over the world. For instance, many women are needed throughout their lives to prevent unsafe or unintended pregnancy [1]. As well, many governments consider family planning as a valuable policy to improve living characteristics of the community [2]. On the other hand, different moderating variables such as cultural beliefs, fears, and unfavorable attitudes are associated with the use of all contraceptives $[3,4]$.

Rapid population growth is a big socioeconomic obstacle facing Yemen, which is one of the poorest countries worldwide. The population size increased from 9.7 million in 1985 to about 25.5 million in 2015 [5]. In 1990, Yemeni government assigned a national population strategy, which was approved as population policy in 1991. The objectives of the strategy had aimed to reduce the population growth rate to $2 \%$ by the year 2000 [6]. Unfortunately, a higher population growth rate of $2.6 \%$ has been estimated since 2010 and this may call for an important improvement in the represents of family planning methods [5].

The modern contraceptive methods: the pill, intrauterine device (IUD), injectable, implant, condom, and spermicidal are used in Yemen. Oral contraceptive pill (OCP) including a combination of an estradiol and a progestin is widely accepted. It accounts for half of the modem family planning methods use in Yemen [7]. Nevertheless, the achievement of an ideal population growth rate in a community requires the combination of a number of measures for the implementation of that strategy. The involvement of the community is a key tool of family planning methods as a development in the understanding of the benefits of contraceptives can significantly raise the attainment and continuance of population growth control [8].

Currently, Yemeni people are facing a serious economic breakdown and incompetent health facilities that has been continuing to be worsted by social instability and outbreaks of regional war and international terrorism. In parallel with this difficulty affecting Yemeni families, this study was aimed to investigate the association of the potential demographic characteristics and perceptions with OCPs use among women in Dhamar area, Yemen. 


\section{Methodology}

\subsection{Study Area and Study Population}

The present survey was carried out in Dhamar district, which is located 100 kilometers south of the capital city of Yemen, Sana'a. This district contains 240,441 people and sits among Dhamar governorate that is involving another 11 districts, which are the catchment areas for Dhamar city's governmental health facilities. Dhamar governorate contains about $1,330,108$ with a population growth rate of $3.04 \%$ [9]. The people still keep their honorable traditions and habits for different occasions. Islamic principles inspirit most of the life aspects including the family regulations and relationships. Governmental centers associated with reproductive health facilities were included in this survey: Dhamar General Hospital, Maternal and Child Health Centre, Yemen Red Crescent, Al-Wehdh Health Centre, Al-Gadad Health Centre, and Al-Homeat Hospital. The study sample was married women who visited these centers during the study time.

\subsection{Study Design}

It was a cross-sectional study that carried out between June 2013 and March 2014 in Dhamar district to investigate the prevalence and predictors of OCPs use among Yemeni women. The sample size was planned assuming an expected frequency of 0.50 , a $95 \%$ confidence level, a 0.05 desired level of absolute precision and a 0.80 response rate. The calculations indicated that the study needs a minimum sample size of 385 and an initial sample size of 480 .

The participants were randomly selected at the reproductive health centers. A total of four hundred (400) women successfully participated in this study. Demographic data and perceptions on use of OCPs were collected from the participants using a translated Arabic pre-tested questionnaire.

The questionnaire was semi-structured that administered to the respondents by trained medical staffs from the health centers. The contribution of all the participants was completely free. A verbal consent was obtained from each woman before commencing data collection. The study has been approved by Thamar University Medical Ethics Committee (TUMEC).

\subsection{Data Analysis}

The IBM SPSS statistical software of version 22.0 was used in this survey. The study variables were described as a percentage $(\%)$. To identify the potential predictors of OCPs use, Poisson regression model incorporating the robust sandwich variance (RSV) was used to develop the prevalence ratio $(\mathrm{PR})$ of OCPs use as the dependent variable by the demographic and perceptions of the participants as the explanatory variables $[10,11]$. The OCPs use variable was dichotomously studied, (no $=0$, yes $=1$ ). Similarly, the explanatory variables were coded as the following: age $(<25$ years $=0, \geq 25$ years $=1$ ); educational level (no formal education $=0, \geq 6$ years formal education $=1)$; employment status (working $=0$, non-working $=1)$; age at marriage $(\geq 20$ years $=0,<20$ years $=1)$; number of living children $(\leq 3$ children $=0,>3$ children $=1)$; fears on use $($ no $=0$, yes $=1)$; economics on preference (no $=0$, yes $=1$ ); seeking behavior (others $=0$, health centers $=1)$. The estimated ratio $(\mathrm{ER}=\mathrm{PR}-$ 1) was then calculated for predicting the estimated prevalence of OCPs. The level of significance ( $\mathrm{P}$ value) in this study was $\leq 0.05$.

\section{Results}

\subsection{General Characteristics of Participants}

The basic data of this survey showed that $13 \%, 54 \%, 21 \%$, and $12 \%$ of women were below 20,20 to 29,30 to 34 , and above 34 years old, respectively. Table 1 shows the general characteristics of the study participants. Most (63.2\%) of the participants were of $\geq 25$ years of age. Almost half (46\%) of the participants had no formal education and the majority (77\%) were non-working. About half of the studied women had $<20$ years at marriage and $>3$ living children.

The vast majority of the participants $(96 \%)$ had no fears on OCP use. However, only $22.8 \%$ of the subjects reported economic matters on preference of this family planning method. Accordingly, most of the participants indicated that they would visit the reproductive health centres for seeking OCPs $(83.3 \%)$.

Table 1. General characteristics of the study participants $(N o=400)$.

\begin{tabular}{ll}
\hline General characteristics & Frequency N (\%) \\
\hline Demographic characteristics & \\
Age & $253(63.2)$ \\
$\geq 25$ years & $147(36.8)$ \\
$<25$ years & $184(46.0)$ \\
Educational level & $216(54.0)$ \\
No formal education & \\
$\geq 6$ years formal education & $308(77.0)$ \\
Employment status & $92(23.0)$ \\
Non-working & $188(47.0)$ \\
Working & $212(53.0)$ \\
Age at marriage & $174(43.5)$ \\
$<20$ years & $226(56.5)$ \\
$\geq 20$ years & \\
Number of living children & \\
$>3$ children & $16(4.0)$ \\
$\leq 3$ children & $384(96.0)$ \\
Perceptions on OCPs use & $91(22.8)$ \\
Fears on use & $309(77.2)$ \\
Yes & \\
No & \\
Economics on preference & \\
Yes & \\
No & \\
Heeking behaviour & \\
Others & \\
\hline
\end{tabular}

\subsection{Prevalence and Distribution of OCPs Use}

The overall prevalence of OCPs use was 33\% (Figure 1). The distribution of OCPs use among the study groups is shown in Table 2. The prevalence of OCPs use among women aged $\geq 25$ years was higher than the prevalence 
among those aged $<25$ years $(45.5 \%$ compared to $11.6 \%$, respectively). Relatively, similar results was reported by the number of children ( $48.3 \%$ vs $21.2 \%)$, and fears on OCPs use $(12.5 \%$ vs $33.9 \%)$.

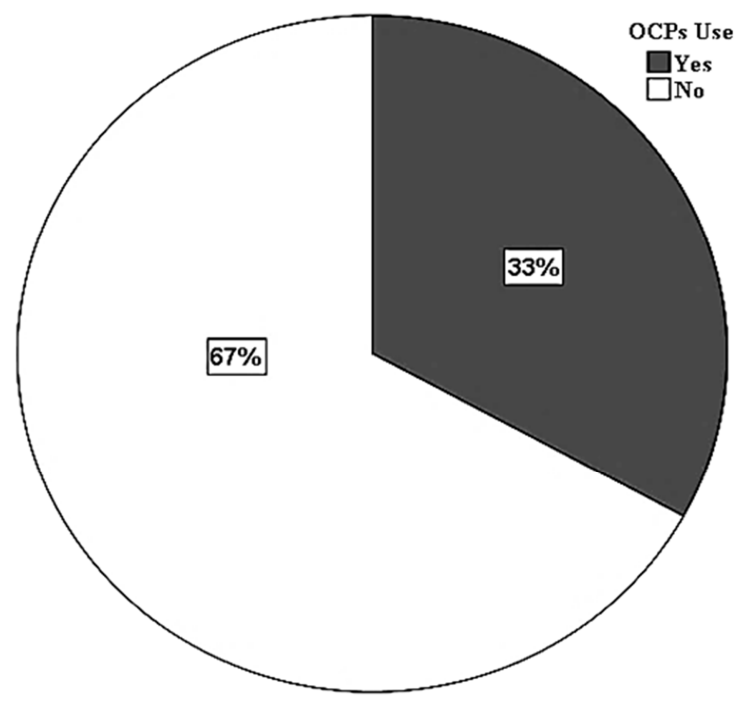

Figure 1. Prevalence of OCPs use among Yemeni women in Dhamar area.

Moreover, $36.0 \%, 41.8 \%, 38.3 \%$, and $35.1 \%$ of the users (compared to $17.9 \%, 25.5 \%, 28.3 \%$, and $26.1 \%$ of the studied groups) had positive OCPs-seeking behavior, no formal education, $<20$ years at marriage, and non-working status, respectively. Conversely, the prevalence of OCPs use was higher among women who had no an economic preference on OCPs (33.7\% vs. $30.8 \%)$.

Table 2. Distribution of OCPS use by characteristics of the participants.

\begin{tabular}{|c|c|c|}
\hline \multirow{2}{*}{ General characteristics } & \multicolumn{2}{|l|}{ OCPs use } \\
\hline & Yes & No \\
\hline \multicolumn{3}{|l|}{ Demographic characteristics } \\
\hline \multicolumn{3}{|l|}{ Age } \\
\hline$\geq 25$ years & $115(45.5)$ & $138(54.5)$ \\
\hline$<25$ years & $17(11.6)$ & $130(88.4)$ \\
\hline \multicolumn{3}{|l|}{ Educational level } \\
\hline No formal education & $77(41.8)$ & $107(58.2)$ \\
\hline$\geq 6$ years formal education & $55(25.5)$ & $161(74.5)$ \\
\hline \multicolumn{3}{|l|}{ Employment status } \\
\hline Non-working & $108(35.1)$ & $200(64.9)$ \\
\hline Working & $24(26.1)$ & $68(73.9)$ \\
\hline \multicolumn{3}{|l|}{ Age at marriage } \\
\hline$<20$ years & $72(38.3)$ & $116(61.7)$ \\
\hline$\geq 20$ years & $60(28.3)$ & $152(71.7)$ \\
\hline \multicolumn{3}{|l|}{ Number of living children } \\
\hline$>3$ children & $84(48.3)$ & $90(51.7)$ \\
\hline$\leq 3$ children & $48(21.2)$ & $178(78.8)$ \\
\hline \multicolumn{3}{|l|}{ Perceptions on OCPs use } \\
\hline \multicolumn{3}{|l|}{ Fears on use } \\
\hline Yes & $2(12.5)$ & $14(87.5)$ \\
\hline No & $130(33.9)$ & $254(66.1)$ \\
\hline \multicolumn{3}{|l|}{ Economics on preference } \\
\hline Yes & $28(30.8)$ & $63(69.2)$ \\
\hline No & $104(33.7)$ & $205(66.3)$ \\
\hline \multicolumn{3}{|l|}{ Seeking behaviour } \\
\hline Health centres & $120(36.0)$ & $213(64.0)$ \\
\hline Others & $12(17.9)$ & $55(82.1)$ \\
\hline
\end{tabular}

\subsection{Prevalence Ratio of OCPs Use}

The prevalence ratio for the association of OCPs use with the explanatory variables is illustrated in Table 3. The following variables were indicated as significant predictors for OCPs use: age, education level, and age of marriage, as well as number of living children, OCPs seeking behavior and fears on OCPs use.

The regression model predicts that the prevalence of OCPs use would significantly increase $30 \%$ times among women $\geq$ 25 years $(\mathrm{PR}=1.30 ; P<0.001)$, and by $22 \%$ times among women having $>3$ living children $(\mathrm{PR}=1.22 ; P<0.001)$. Accordingly, women with no formal education and married $<$ 20 years would relatively show higher prevalence ratio of OCPs use $(\mathrm{ER}=13 \%$; $\mathrm{PR}=1.13 ; P<0.001, \mathrm{ER}=8 \%$; $\mathrm{PR}=$ $1.08 ; P<0.05$, respectively).

Regarding the studied women's attitude on safety of OCPs, fears of adverse outcomes revealed a significant decrease in the use of OCPs of $16 \%$ times (PR $=0.84 ; P<0.05)$. On the other hand, seeking the pills from health centers significantly increases the prevalence of OCPs use by $15 \%$ times, $(\mathrm{PR}=$ 1.15; $P<0.001)$. On the other hand, the employment status and economics preference were found to be insignificant predictors for using OCPs.

\section{Discussion}

This study is the first to investigate the predictors of OCPs use in Dhamar governorate, which is directly essential to determine the nature of the adjustments required for enhancing the family planning intervention. Findings of the present study indicated that the OCPs prevalence rate for Yemeni married women is 33 percent. There were significant differences between the studied groups in terms of their demographic characteristics, practices, and attitudes on OCPs use. This could be explained by the higher age and number of living children of the users. In addition, religious beliefs and educations along with fears of adverse complications among the nonusers may contribute to their attitude, practice, and preference on OCPs use. Generally, Islamic beliefs and educations encourage reproduction and prohibit illegal abortions; they attribute sustenance to Allah (God) and fear of poverty to Satan (Devil) $[12,13]$.

The results of the present study indicated that the prevalence of OCPs use in Yemen has really enlarged, from $3 \%$ in 1991 to $33 \%$ in 2014 . However, almost half of the users and nonusers had more than three living children. Accordingly, the age differentials for OCPs prevalence showed that the majority of OCPs users were women of 25 years and above, and this was significantly associated with the number of children. Moreover, it has been reported that about one third of Yemeni women have an unmet need for family planning [14]. Therefore, this report of an enlarged OCPs practice was not harmonized by a comparable decrease in the number of children among the studied women. 
Table 3. Prevalence ratio of OCPs use among Yemeni women in Dhamar area $(n=400)$.

\begin{tabular}{|c|c|c|c|c|}
\hline Variables & PR & 95\% C. I. & ER \% & $P$ \\
\hline \multicolumn{5}{|l|}{ Age } \\
\hline$\geq 25$ years & 1.30 & $1.23-1.39$ & 30 & $<0.001$ \\
\hline$<25$ years & 1 & & & \\
\hline \multicolumn{5}{|l|}{ Educational level } \\
\hline No formal education & 1.13 & $1.06-1.21$ & 13 & $<0.001$ \\
\hline$\geq 6$ years formal education & 1 & & & \\
\hline \multicolumn{5}{|l|}{ Employment status } \\
\hline Non-working & 1.07 & $0.99-1.16$ & 7 & ns \\
\hline Working & 1 & & & \\
\hline \multicolumn{5}{|l|}{ Age at marriage } \\
\hline$<20$ years & 1.08 & $1.01-1.16$ & 8 & $<0.05$ \\
\hline$\geq 20$ years & 1 & & & \\
\hline \multicolumn{5}{|l|}{ Number of living children* } \\
\hline$>3$ children & 1.22 & $1.14-1.31$ & 22 & $<0.001$ \\
\hline$\leq 3$ children & 1 & & & \\
\hline \multicolumn{5}{|l|}{ Fears on use } \\
\hline Yes & 0.84 & $0.73-0.98$ & -16 & $<0.05$ \\
\hline No & 1 & & & \\
\hline \multicolumn{5}{|l|}{ Economics on preference } \\
\hline Yes & 0.98 & $0.90-1.06$ & -2 & ns \\
\hline No & 1 & & & \\
\hline \multicolumn{5}{|l|}{ Seeking behaviour } \\
\hline Health centres & 1.15 & $1.06-1.26$ & 15 & $<0.001$ \\
\hline Others & 1 & & & \\
\hline
\end{tabular}

PR: prevalence risk; CI: confidence interval; ER: estimated ratio; P: level of significance; ns: P > 0.05.

Education plays a significant role in practices of family planning methods. Previous studies showed a significant association between the countryside communities and the unmet need for contraception, in particular OCPs and intrauterine device (IUD) [15]. The basic findings of this study found that the educated participants utilized more contraceptive methods such as injectable, condom, safe period, and spermicidal. In agreement with these results, it is accepted that the inadequate knowledge of the participants may produce a higher need for OCPs.

Promising results about contraceptives-seeking behavior were reported among almost three-quarters of the study population; $90.9 \%(120 / 132)$ of the users and 79.5\% (213/268) of the nonuser participants seek contraceptives at health centers. This could be due to the wide availability of family planning methods and access to their facilities to all Yemeni throughout the country. However, the better practical knowledge of seeking contraceptives at health centers reported by the users considerably reflected a higher prevalence of OCPs use than the nonusers. This was in agreement with the previous study in urban and rural areas of India [16]. The study reported that the practices of married women on family planning significantly linked to their knowledge.

There was an important message in the responses of the participants of this study regarding their attitude on OCPs use. The findings showed that the use of OCPs is significantly influenced by fears of the participants. They were influenced by the mistaken beliefs that OCPs use is linked with the risk of infertility and cancers. In some settings, responses of some participants indicated that birth control has inadequate support among their families. This could be due to the lack of information about the benefits of OCPs among such households, and consequently many couples may be hesitant to use family planning. Hence, it is important to overcome these barriers about highly available contraceptive methods. Improvement of the population policy to contain participation of the community in the family planning programs could be of great outcomes.

\section{Conclusions}

The present study showed that one-third of Yemeni women are used OCPs to control birth. The use of OCPs is associated with women's demographic characteristics, attitudes, and practices. However, the obstetric characteristics of the studied women give an indication of unmet need for family planning methods. The participation of community is one of the main policies to make better the use of contraceptives. Improving the knowledge of Yemenis about the benefits of family planning could have a promise appreciate in removing the misconceptions about the contraceptives methods. It is also significant to reconsider the strategies carried out to manage and update obstetricians and gynecologists regarding use of long-acting contraceptives. Further community-based studies about the association of Quran recommendations and tribal principles on use of contraceptives are interested.

\section{Acknowledgments}

The authors would like to acknowledge the staffs of Dhamar General Hospital, Maternal and Child Health Centre, Yemen Red Crescent, Al-Wehdh Health Centre, Al-Gadad 
Health Centre, and Al-Homeat Hospital for their generous support and cooperation in the collection of the study data. We also thankfully appreciate the study population for their participation in this study.

\section{References}

[1] J. J. Frost, S. Singh and L. B. Finer, "Factors associated with contraceptive use and nonuse, United States, 2004," Perspectives on Sexual and Reproductive Health, vol. 39, pp. 90-99, 2007.

[2] S. Z. Sherpa, M. Sheilini and A. Nayak, "Knowledge, attitude, practice and preferences of contraceptive methods in Udupi District, Karnataka," Journal of Family and Reproductive Health, vol. 7, pp. 115-120, 2013.

[3] J. O. Friedman, "Factors associated with contraceptive satisfaction in adolescent women using the IUD,"J Pediatr Adolesc Gynecol., 28, pp. 38-42, 2015.

[4] L. Bahamondes, M. Y. Makuch, I. Monteiro, V. Marin, R. Lynen, "Knowledge and attitudes of Latin American obstetricians and gynecologists regarding intrauterine contraceptives, " International Journal of Women's Health, 7, pp. 717-722, 2015.

[5] United Nations, World Population Prospects: The 2012 Revision. [Online]. Available: http://esa.un.org/unpd/wpp/unpp/panel_indicators.htm. [Accessed November 2015]

[6] Central Statistical Organization (CSO) [Yemen] and Macro International Inc. (MI), Yemen Demographic and Maternal and Child Health Survey 1997. Calverton, Maryland: CSO and MI, 1998.

[7] Central Statistical Organization (CSO) [Yemen], Pan Arab Project for Child Development (PAPCHILD) [Egypt] and Macro International Inc. (Ml), Yemen Demographic and Maternal and Child Health Survey 1991/1992. Calverton, Maryland: CSO and MI, 1994.
[8] B. F. Reading, "Growth in world contraceptive use stalling; 215 million women's needs still unmet, 2012." [Online]. Available: http://www.earth-policy.org/data_highlights/2012/highlights26. [Accessed December 2015].

[9] Public Health and Population Office of Dhamar Governorate, Primary Health Care Management, Proposal of the National Campaign for Controlling Schistosomiasis 2014, unpublished. Dhamar, Yemen: Public Health and Population Office of Dhamar Governorate, 2014.

[10] J. Lee, C. S. Tan and K. S. Chia, "A Practical Guide for Multivariate Analysis of Dichotomous Outcomes," Annals Academy of Medicine, vol. 38, pp. 714-719, 2009.

[11] M. Coutinho, M. Scazufca and P. Menezes, "Methods for estimating prevalence ratios in cross sectional studies," Rev Saúde Pública, vol. 42, pp. 1-6, 2008.

[12] The Nobel Qur'an, Surah Al-Isra, Verse 31. [Online]. Available: $\mathrm{http}$ ://en.noblequran.org/quran/surah-al-isra/ayat-30/ [Accessed December 2015].

[13] The Nobel Qur'an, Surah Al-Baqarah, Verse 268. [Online]. Available:

http://en.noblequran.org/quran/surah-al-baqarah/ayat-268/ [Accessed December 2015].

[14] Ministry of Public Health and Population and Central Statistical Organization (CSO) [Yemen], Pan Arab Program for Family Health (PAPFAM) [Egypt] and MEASURE DHS, ICF International. Yemen National Health and Demographic Survey 2013. Rockville, Maryland: CSO, PAPFAM and ICF, 2014.

[15] W. Hameed, S. K. Azmat, M. Ali, et al., "Women's empowerment and contraceptive use: the role of independent versus couples' decision-making, from a lower middle income country perspective," PLoS One, 9, 9. 2014.

[16] P. D. Rao and M. S. Babu, "Knowledge and use of contraception among Racha Koyas of Andhra Pradesh," Anthropologist, 7, pp. 115-119, 2005. 